\title{
Identification of novel Babesia and Theileria species in South African giraffe (Giraffa camelopardalis, Linnaeus, 1758) and roan antelope (Hippotragus equinus, Desmarest 1804)
}

\author{
Marinda C. Oosthuizen ${ }^{\text {a }}$, Basil A. Allsopp ${ }^{a}$, Milana Troskie ${ }^{a}$, Nicola E. Collins ${ }^{\text {a }}$ and Barend L. \\ Penzhorn $^{a}$
}

${ }^{a}$ Department of Veterinary Tropical Diseases, Faculty of Veterinary Science, University of Pretoria, Private Bag X04, Onderstepoort 0110, South Africa

\begin{abstract}
Blood specimens were received from five cases in which young adult giraffe, from different geographic origins in South Africa, showed sudden onset of disease and subsequently died. Additional specimens from two translocated giraffe, as well as one specimen from a roan antelope, were also included in the study. Blood slides from some of these animals showed the presence of piroplasms. DNA was extracted; the V4 hypervariable region of the $18 S$ rRNA gene amplified and analyzed using the Reverse Line Blot (RLB) hybridization assay. PCR products failed to hybridize with any of the Babesia or Theileria speciesspecific probes, and only hybridized with the Babesia/Theileria genus-specific probe suggesting the presence of a novel species or variant of a species. Full-length 18S rDNA was amplified, cloned and the recombinants were sequenced. $18 S$ rRNA gene sequence similarity analysis revealed the presence of novel piroplasm species in both healthy giraffe and a roan antelope and clinically sick or dead giraffe. Phylogenetic analysis grouped five of these organisms in the Babesia sensu stricto clade and three in the Theileria sensu stricto clade. Although parasites were observed in blood smears, there is no direct evidence that piroplasmosis caused the death of five giraffe, although it certainly seems to be likely.
\end{abstract}

Keywords: Theileria; Babesia; Giraffe; Roan antelope; Reverse Line Blot hybridization assay; 18S rRNA gene; Phylogenetic analysis

\section{Introduction}

Africa is a vast and exotic continent with an abundant wildlife resource of unique value. Wildlife and livestock contribute significantly to the economies of most sub-Saharan African countries, but the variety and abundance of wildlife in Africa is shrinking fast as human populations grow and encroach on once wild land. Disease is also becoming increasingly recognized as a threat to wildlife conservation, especially for endangered species. Furthermore, wildlife frequently act as reservoir hosts of various viral, bacterial and protozoal pathogens of veterinary and zoonotic importance, and since the wildlife hosts are usually asymptomatic, the danger to domestic animals and humans may be overlooked (Worthington \& Bigalke, 2001). Severe disease outbreaks do occur in wild animals, however, for example, when a naïve 
animal is introduced into an endemic area or when a latent infection is activated by stress factors such as those which occur as a result of translocation (Nijhof et al., 2005).

Piroplasms are tick-borne intracellular apicomplexan parasites which inhabit erythrocytes, and sometimes other cells, of vertebrates. The two main genera, Theileria and Babesia, contain many species of major veterinary and economic importance. Wild ruminants harbor a wide variety of piroplasms, some of which are pathogenic, while others are considered moderately pathogenic or benign. By far the most pathogenic and economically significant species of Theileria in eastern, central and southern Africa is Theileria parva, which causes East Coast fever (ECF), Corridor disease and January disease in cattle (Uilenberg et al., 1982 and Perry et al., 1991). Theileria parva is frequently fatal in cattle but causes only subclinical infections in African buffalo (Syncerus caffer), the host in which it appears to have evolved (Norval et al., 1992). Other ruminants suffer from fatal infections with piroplasms. Theileria taurotragi infection has been reported to be fatal in eland (Taurotragus oryx), although infections in cattle are usually subclinical and not readily detected (Grootenhuis et al., 1979 and Grootenhuis et al., 1980). Babesia bicornis was identified in four fatal cases of babesiosis in black rhinoceros (Diceros bicornis) in South Africa and Tanzania (Nijhof et al., 2003). Three of the four rhinoceros died soon after capture, during periods of nutritional or pregnancy-related stress, or during extreme climatic conditions. Theileria bicornis was also identified in the same study, but the authors found no evidence that it caused disease in black rhinoceros. In 2005 Nijhof and colleagues reported on cases of fatal theileriosis (cytauxzoonosis) occurring after translocation in roan antelope (Hippotragus equinus), sable antelope (Hippotragus niger) and greater kudu (Tragelaphus strepsiceros) in South Africa. The parasites detected were Theileria sp. (sable) in roan and sable antelope and Theileria sp. (kudu) in the greater kudu. Theileria sp. (duiker) was detected in a grey duiker (Sylvicapra grimmia) that died on a private game farm in Gauteng province, South Africa (Nijhof et al., 2005). Recently, Babesia sp. (sable) was identified in a sable antelope that died from an unknown illness on a game ranch in the Limpopo province, South Africa (Oosthuizen et al., 2008). While the parasite was observed in blood smears, there was no direct evidence that it was the cause of death. Piroplasms in giraffe were first reported in Kenya: Theileria spp. in both Masai (Giraffa camelopardalis tippelskirchi) and reticulated (G. c. reticulata) giraffe, as well as Babesia spp. in reticulated giraffe (Brocklesby and Vidler, 1965). These authors also recorded a parasite of doubtful identity in the renal corpuscles of a reticulated giraffe which resembled Cytauxzoon. Fatal cytauxzoonosis was reported in a giraffe that had been translocated from Namibia to northern KwaZulu-Natal, South Africa (McCully et al., 1970). The diagnosis was based on the presence of small intra-erythrocytic piroplasms, schizogony in the Kupffer cells and hepatocytes, as well as enlargement of these parasitized cells and their tendency to become multinuclear and form syncytia. The exact origin of the giraffe was unknown but the authors speculated that it may have come from an area in Namibia free of the disease and could consequently 
have lacked immunity. Small intra-erythrocytic trophozoites resembling Cytauxzoon sp. were seen on blood smears of two giraffe from the Etosha National Park, Namibia (Krecek et al., 1990).

In 1974, a mortality rate of 57\% was reported among roan antelope from the Percy Fyfe Nature Reserve in the former Transvaal province of South Africa, with most deaths occurring within the first 12 weeks after birth (Wilson et al., 1974). Cytauxzoonosis was incriminated as the cause of death of two of the young roan calves. The authors could not rule out the stress of being in captivity as the trigger relapseinducing factor in the pathogenesis, they could only speculate that cytauxzoonosis was the primary cause of death. Two fatal cases of theileriosis occurred in roan antelope after translocation from Togo and Benin in West Africa to a private game farm in southern Mpumalanga province, South Africa (Nijhof et al., 2005). The cause of death was attributed to the presence of Theileria sp. (sable). These authors also suggested, based on the close phylogenetic relationship between members of the genera Theileria and Cytauxzoon, that the taxonomic status of the aetiological agents of theileriosis in African antelope species needed to be clarified.

In the current study, specimens were received from five cases in which young adult giraffe, from different geographic origins in South Africa, showed sudden onset of disease and subsequently died. Additional specimens from two translocated giraffe, as well as one specimen from a roan antelope, were also included in the study. Blood slides from some of these animals showed the presence of piroplasms. The aim of the study was to identify the parasites using $18 \mathrm{~S}$ rRNA gene sequence analysis and to determine their phylogenetic relationships to other piroplasms previously identified in African wild ruminants.

\section{Materials and methods}

\subsection{Origin and extraction of DNA}

Blood smears, EDTA blood and/or spleen samples were collected from giraffe $(n=7)$ and roan antelope $(n=1)$ (Table 1). Five of the giraffe had died from the sudden onset of a peracute disease, while the two remaining giraffe and the roan antelope were animals from which routine samples were taken during translocation. DNA was extracted from $200 \mu$ of blood or $25 \mathrm{mg}$ of tissue using the QIAamp ${ }^{\circledR}$ DNA Extraction Kit (QIAGEN, Southern Cross Biotechnologies). Extracted DNA was eluted in $100 \mu$ l elution buffer and stored at $4{ }^{\circ} \mathrm{C}$ until further analysis. 
Table 1. Origin of samples received for this study.

\begin{tabular}{|l|l|l|l|}
\hline Host & Place of origin & Gender and age & Submitted by \\
\hline $\begin{array}{l}\text { Giraffe } \\
229\end{array}$ & Not known & Not known & James Hill (2004) \\
\hline $\begin{array}{l}\text { Giraffe } \\
544\end{array}$ & Mauricedale Game Ranch, Mpumalanga & Female (young adult) & Justin Benade (2007) \\
\hline $\begin{array}{l}\text { Giraffe } \\
0105\end{array}$ & Spioenkop, KwaZulu-Natal & Male (2-3 years) & $\begin{array}{l}\text { Natalie Armour } \\
\text { (2005) }\end{array}$ \\
\hline $\begin{array}{l}\text { Giraffe } \\
1505\end{array}$ & Game farm, Waterberg, Limpopo & Female (young adult) & $\begin{array}{l}\text { Werner Nieuwoudt } \\
\text { (2005) }\end{array}$ \\
\hline $\begin{array}{l}\text { Giraffe } \\
224\end{array}$ & $\begin{array}{l}\text { Reddersburg, Free State (originally } \\
\text { from Namibia) }\end{array}$ & Female (2 years) & Pierre Nel (2004) \\
\hline $\begin{array}{l}\text { Giraffe } \\
0405\end{array}$ & Kimberley, Northern Cape & Male (2 years) & Jana Pretorius (2005) \\
\hline $\begin{array}{l}\text { Giraffe } \\
0505\end{array}$ & Kimberley, Northern Cape & Female (2 years) & Jana Pretorius (2005) \\
\hline Roan 571 & Mkhaya Wildlife Sanctuary, Swaziland & $\begin{array}{l}\text { Gender not known (3-month- } \\
\text { old calf) }\end{array}$ & Johan Steyl (2006) \\
\hline
\end{tabular}

\subsection{Reverse Line Blot (RLB) hybridization}

The Theileria and Babesia genus-specific primers RLB F2 [5'-GAC ACA GGG AGG TAG TGA CAA G-3'] and biotin-labeled RLB R2 [5'-Biotin-CTA AGA ATT TCA CCT CTA ACA GT-3'] were used to amplify the V4 hypervariable region of the parasite 18S rRNA gene using a touchdown PCR programme as previously described (Nijhof et al., 2003 and Nijhof et al., 2005). The PCR amplicons were analyzed using the RLB hybridization technique as described by Nijhof and colleagues (2005). Theileria and Babesia genus-specific probes and 27 species-specific probes, including T. bicornis (Nijhof et al., 2003), Theileria sp. (kudu) (Nijhof et al., 2005), Theileria sp. (sable) (Nijhof et al., 2005), Babesia sp. (sable) (Oosthuizen et al., 2008), and B. bicornis (Nijhof et al., 2003) were included on the membrane (Table 2). 
Table 2. Genus and species-specific RLB probes used in this study.

\begin{tabular}{|c|c|}
\hline Oligonucleotide probe & Sequence $\left(5^{\prime}-3^{\prime}\right)^{*}$ \\
\hline Theileria/Babesia genus-specific & ATT AGA GTG TTT CAA GCA GAC \\
\hline Theileria genus-specific & ATT AGA GTG TTT CAA GCA GAC \\
\hline Babesia genus-specific 1 & ATT AGA GTG TTT CAA GCA GAC \\
\hline Babesia genus-specific 2 & ACT AGA GTG TTT CAA ACA GGC \\
\hline Babesia bicornis & TTG GTA AAT CGC CTT GGT C \\
\hline Babesia bigemina & CGT TTT TTC CCT TTT GTT GG \\
\hline Babesia bovis & CAG GTT TCG CCT GTA TAA TTG AG \\
\hline Babesia caballi & GTG TTT ATC GCA GAC TTT TGT \\
\hline Babesia canis & TGC GTT GAC GGT TTG AC \\
\hline Babesia divergens & ACT RAT GTC GAG ATT GCA C \\
\hline Babesia felis & TTA TGC GTT TTC CGA CTG GC \\
\hline Babesia gibsoni & CAT CCC TCT GGT TAA TTT G \\
\hline Babesia major & TCC GAC TTT GGT TGG TGT \\
\hline Babesia microti & GRC TTG GCA TCW TCT GGA \\
\hline Babesia rossi & CGG TTT GTT GCC TTT GTG \\
\hline Babesia sp. (sable) & GCG TTG ACT TTG TGT CTT TAG C \\
\hline Babesia vogeli & AGC GTG TTC GAG TTT GCC \\
\hline Theileria annulata & CCT CTG GGG TCT GTG CA \\
\hline Theileria bicornis & GCG TTG TGG CTT TTT TCT G \\
\hline Theileria buffeli & GGC TTATTT CGG WTT GAT TTT \\
\hline Theileria equi & TTC GTT GAC TGC GYT TGG \\
\hline Theileria lestoquardi & CTT GTG TCC CTC CGG G \\
\hline Theileria mutans & CTT GCG TCT CCG AAT GTT \\
\hline Theileria ovis & TTG CTT TTG CTC CTT TAC GAG \\
\hline Theileria parva & GGA CGG AGT TCG CTT TG \\
\hline Theileria separata & GGT CGT GGT TTT CCT CGT \\
\hline Theileria sp. (buffalo) & CAG ACG GAG TTT ACT TTG T \\
\hline
\end{tabular}




\begin{tabular}{|l|l|}
\hline Oligonucleotide probe & Sequence $\left(\mathbf{5}^{\prime}-\mathbf{3}^{\prime}\right)^{*}$ \\
\hline Theileria sp. (kudu) & CTC CAT TGT TTCTTT CCT TTG \\
\hline Theileria sp. (sable) & GCT GCA TTG CCT TTT CTC C \\
\hline Theileria taurotragi & TCT TGG CAC GTG GCT TTT \\
\hline Theileria velifera & CCT ATT CTC CTT TACGAG T \\
\hline * Symbols used to indicate degenerate positions: $\mathrm{R}=\mathrm{A} / \mathrm{G} ; \mathrm{W}=\mathrm{A} / \mathrm{T} ; \mathrm{Y}=\mathrm{C} / \mathrm{T}$. \\
\hline
\end{tabular}

\subsection{Cloning and sequencing}

The near full-length parasite 18S rRNA gene was amplified using primers Nbab_1F [5'-AAG CCA TGC ATG TCT AAG TAT AAG CTT TT-3'] and Nbab_1R [5'-CTT CTC CTT CCT TTA AGT GAT AAG GTT CAC-3'] (Oosthuizen et al., 2008). The amplification mixture contained $2.5 \mu 1$ DNA ( $12.5 \mu$ Expand High Fidelity PCR Master mix (Roche Diagnostics, Mannheim, Germany), a final concentration of $0.1 \mu \mathrm{M}$ for each primer, and nuclease-free water to a total volume of $25 \mu \mathrm{l}$. Each PCR reaction was duplicated four times to obtain a total volume of $100 \mu 1$. Amplification was performed with an initial denaturing at $94^{\circ} \mathrm{C}$ for 2 min followed by 40 cycles of $94{ }^{\circ} \mathrm{C}$ for $30 \mathrm{~s}, 55^{\circ} \mathrm{C}$ for 1 min and $72{ }^{\circ} \mathrm{C}$ for $1 \mathrm{~min}$. Final extension was at $72{ }^{\circ} \mathrm{C}$ for $7 \mathrm{~min}$ whereafter the products were stored at $4{ }^{\circ} \mathrm{C}$. DNA amplicons from the four PCRs per sample were pooled before purification using the QIAquick PCR Purification Kit (QIAGEN, Southern Cross Biotechnologies). This pooling procedure was designed so that if sequence errors originated early in any one of the reactions, the resulting amplicon would contain $<25 \%$ of the erroneous sequence. The purified amplicons were cloned into the pGEM $^{\circledR}$-T Easy vector (Promega pGEM-T Easy Vector System, Promega, Madison, USA) according to the manufacturer's instructions and six recombinant plasmids per sample were directly sequenced using the ABI BigDye $\mathrm{CM}^{\mathrm{TM}}$ Terminator Cycle Sequencing Ready Reaction kit (PE Applied Biosystems), 350 ng plasmid DNA and 3.2 pmol of primer. The primers used for sequencing were RLB F2, RLB R2, Nbab_1F, Nbab_1R BT18S_2F, BT18S_3F, BT18S_4F and BT18S_4R (Oosthuizen et al., 2008). Purified products were analyzed on an ABI3100 genetic analyzer at the Agricultural Research Council-Onderstepoort Veterinary Institute (ARC-OVI, South Africa) sequencing facility. The 18S rRNA gene sequence data obtained were assembled and edited using GAP4 of the Staden package (version 1.6.0 for Windows) (Bonfield et al., 1995, Staden, 1996 and Staden et al., 2000). A search for similar sequences in GenBank was performed using BLASTn (Altschul et al., 1990). 


\subsection{Phylogenetic analysis}

CLUSTAL W (Thompson et al., 1994) was used to align the eight new sequences with a previously published sequence profile from related organisms (Allsopp and Allsopp, 2006). The final alignment comprised 64 18S rRNA sequences (Table 3): 61 were from species of piroplasms and three (Sarcocystis muris, Prorocentrum micans and Toxoplasma gondii) were included as outgroups to root the phylogenetic tree. The aligned sequences were subjected to maximum likelihood phylogenetic analysis using PHYML (Guindon and Gascuel, 2003) using the following parameters: substitution model HKY 85; transition/transversion ratio, proportion of invariable sites and gamma distribution parameter all estimated from the data; 8 substitution rate categories; initial neighbor joining tree optimized for topology, branch lengths and rate parameters; 100 bootstrap replicates performed.

Table 3. GenBank Accession numbers of organisms used in the phylogenetic analysis.

\begin{tabular}{|l|l|l|l|}
\hline Accession no. & Organism & Accession no. & Organism \\
\hline FJ213581 & Babesia sp. roan 571 & AY596279 & Babesia orientalis \\
\hline FJ213582 & Theileria sp. giraffe $0405^{\dagger}$ & AY603400 & Babesia ovata \\
\hline FJ213583 & Theileria sp. giraffe 0505 & AY726011 & Theileria capreoli \\
\hline FJ213580 & Babesia sp. giraffe 229 & AY726556 & Babesia sp. Kashi 1 \\
\hline FJ213584 & Theileria sp. giraffe 224 & AY726557 & Babesia sp. Kashi 2 \\
\hline FJ213577 & Babesia sp. giraffe 544 & AY735130 & Theileria cervi Wisconsin elk \\
\hline FJ213578 & Babesia sp. giraffe 0105 & AY789076 & Babesia divergens \\
\hline FJ213579 & Babesia sp. giraffe $1505^{\dagger}$ & DQ111766 & Babesia canis vogeli Sudan \\
\hline AB049999 & Babesia rodhaini Japan & DQ159073 & Babesia sp. Xinjiang \\
\hline AF078815 & Theileria mutans Trans Mara 1 & DQ200887 & Babesia poelea \\
\hline AF097993 & Theileria velifera & DQ641260 & Theileria sp. (buffalo) \\
\hline AF158700 & Piroplasmida gen. sp. WA1 & EU277003 & Theileria sinensis \\
\hline AF158701 & Piroplasmida gen. sp. WA2 & EU376016 & Babesia sp. (sable) \\
\hline AF158702 & Babesia conradae & EU376017 & Babesia occultans \\
\hline AF158703 & Piroplasmida gen. sp. CA1 & L02366 & Theileria parva \\
\hline AF158708 & Piroplasmida gen. sp. BH1 & L19077 & Babesia bovis South Africa \\
\hline AF175300 & Babesia gibsoni Asia 1 & L19079 & Babesia canis South Africa \\
\hline
\end{tabular}




\begin{tabular}{|l|l|l|l|}
\hline Accession no. & Organism & Accession no. & Organism \\
\hline AF175301 & Babesia gibsoni Asia 2 & L19080 & Cytauxzoon felis \\
\hline AF244911 & Babesia leo & L19081 & Theileria sp. (sable) \\
\hline AF244912 & Babesia felis & L19082 & Theileria taurotragi \\
\hline AF244913 & Babesia sp. caracal A & $\mathrm{L} 31922$ & Babesia bovis Mexico Mo7 \\
\hline AF245279 & Theileria youngi & $\mathrm{M} 14649$ & Prorocentrum micans \\
\hline AF419313 & Babesia bicornis & $\mathrm{M} 64243$ & Theileria annulata \\
\hline AF499604 & Theileria bicornis & $\mathrm{M} 64244$ & Sarcocystis muris \\
\hline AY072926 & Babesia canis canis Croatia & $\mathrm{M} 87565$ & Babesia rodhaini \\
\hline AY260171 & Theileria ovis & $\mathrm{U} 09833$ & Babesia microti \\
\hline AY260175 & Theileria separata & $\mathrm{U} 09834$ & Babesia sp. bovine South Africa \\
\hline AY260178 & Babesia ovis & $\mathrm{X} 59604$ & Babesia bigemina \\
\hline AY260179 & Babesia motasi & $\mathrm{X} 68523$ & Toxoplasma gondii \\
\hline AY371198 & Babesia canis vogeli USA & $\mathrm{Z} 15104$ & Babesia caballi \\
\hline AY485690 & Cytauxzoon manul & $\mathrm{Z} 15105$ & Theileria equi \\
\hline AY508470 & Theileria annulata Turkey 6 & $\mathrm{Z} 15106$ & Theileria buffeli Marula \\
\hline & & \\
\hline
\end{tabular}

${ }^{\dagger}$ Denotes organism identified in this study.

\subsection{Nucleotide sequence accession numbers}

The 18S rRNA gene sequences of the eight new organisms observed in this study were submitted to GenBank. All 64 sequences included in the phylogeny, together with their GenBank accession numbers, are listed in Table 3.

\section{Results}

Five of the giraffe examined in this study were young adults of about 2 years of age which had died from the sudden onset of a peracute disease which appeared to affect many organ systems. Some of the clinical signs noted were: severe depression, recumbency and severe weakness, hypothermia, dyspnoea, rumen stasis and oedema of the sclera and conjunctiva (Table 4). Post-mortem findings included haemoglobinuria, haemopericardium and macroscopic necrotic foci in the liver (Table 4). The other three samples (Table 4) were taken routinely during translocation from two further giraffe and a roan antelope 
which were apparently healthy. Blood smears were available from only three of the giraffe, and microscopic examination demonstrated the presence of a Babesia-like parasite in samples Giraffe 0105 and Giraffe 229, and a Theileria-like parasite in Giraffe 224 (Fig. 1).

Table 4. Summary of clinical signs and/or post-mortem findings in hosts.

\begin{tabular}{|c|c|c|}
\hline Host & Clinical signs and/or post-mortem findings & Post-mortem diagnosis \\
\hline $\begin{array}{l}\text { Giraffe } \\
229\end{array}$ & Not known & Not available. \\
\hline $\begin{array}{l}\text { Giraffe } \\
544\end{array}$ & $\begin{array}{l}\text { Found with hind limb peresis, died shortly afterwards. Pale } \\
\text { mucus membranes, pigmenturia and lymphoid hypoplasia. } \\
\text { Severe tick burden. }\end{array}$ & $\begin{array}{l}\text { Terminal babesiosis while suffering } \\
\text { from suspected unknown } \\
\text { immunosuppressive condition. }\end{array}$ \\
\hline $\begin{array}{l}\text { Giraffe } \\
0105\end{array}$ & $\begin{array}{l}\text { Rapid death. Lung congestion, haemaglobinuria, } \\
\text { haemopericardium and macroscopic foci in liver. Ticks } \\
\text { collected: Rhipicephalus appendiculatus. }\end{array}$ & $\begin{array}{l}\text { Histopathology suggestive of } \\
\text { babesiosis. }\end{array}$ \\
\hline $\begin{array}{l}\text { Giraffe } \\
1505\end{array}$ & $\begin{array}{l}\text { Adult female, sudden onset of illness, recumbent in the } \\
\text { morning, dead by the afternoon, frothy nasal discharge and } \\
\text { regurgitated rumen content. }\end{array}$ & Not available. \\
\hline $\begin{array}{l}\text { Giraffe } \\
224\end{array}$ & $\begin{array}{l}\text { Sudden onset of clinical signs and peracute course of } \\
\text { disease, severe depression, recumbency and severe } \\
\text { weakness, hypothermia, dyspnoea, rumen stasis and oedema } \\
\text { of the sclera and conjunctiva. }\end{array}$ & $\begin{array}{l}\text { Animal could not adapt, complicated } \\
\text { by possible Babesia sp. infection. }\end{array}$ \\
\hline $\begin{array}{l}\text { Giraffe } \\
0405\end{array}$ & Not applicable, samples taken on translocation. & Not applicable. \\
\hline $\begin{array}{l}\text { Giraffe } \\
0505\end{array}$ & Not applicable, samples taken on translocation. & Not applicable. \\
\hline $\begin{array}{l}\text { Roan } \\
571\end{array}$ & Not applicable. & Not applicable. \\
\hline
\end{tabular}


(a)

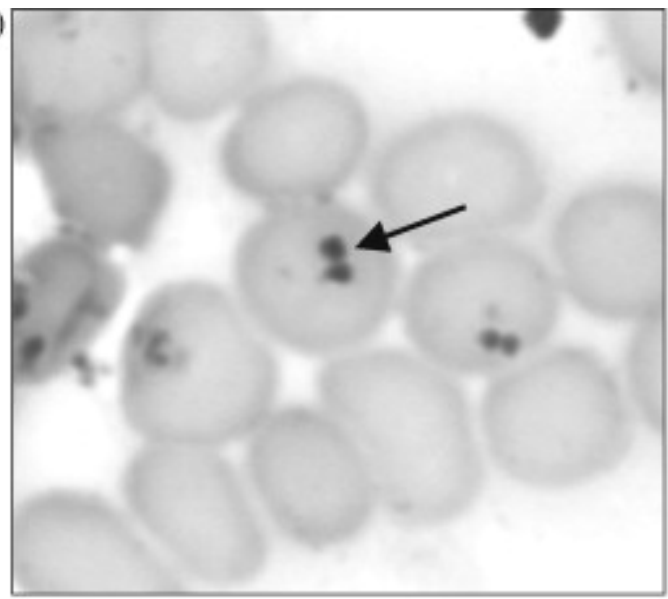

(c)

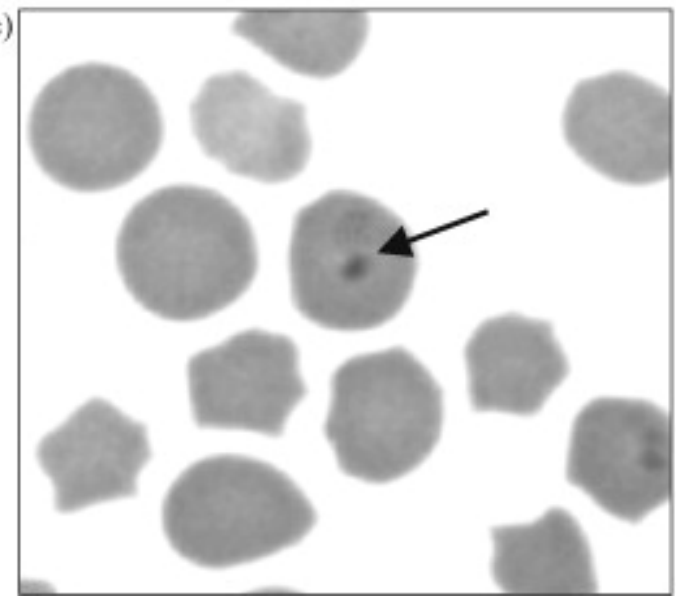

(b)

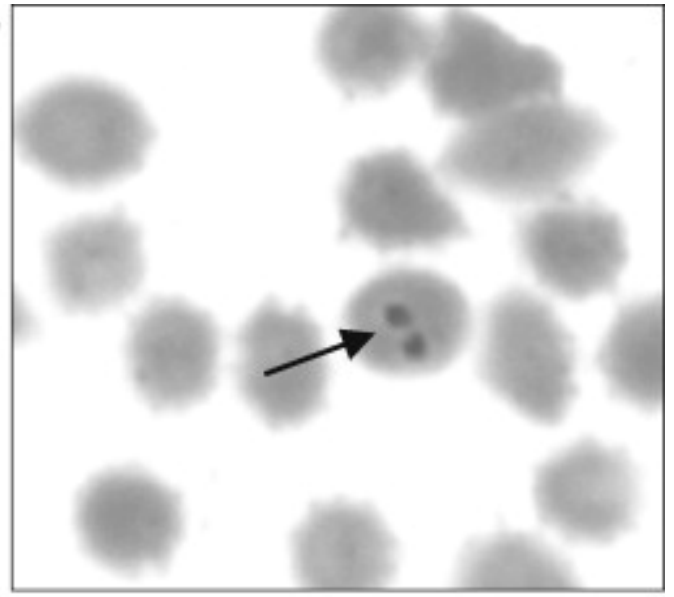

Fig. 1. Light microscopy of thin blood smears showing piroplasm parasites present in (a) giraffe 0105, (b) giraffe 229 and (c) giraffe 224.

The Reverse Line Blot results showed that the PCR products amplified from all seven of the giraffe specimens as well as from the roan antelope hybridized only with the Babesia/Theileria genus-specific probe, and not with any of the Babesia or Theileria species-specific probes present on the blot. Six of the cloned 18S rRNA genes were sequenced from each sample and in each case the six sequences were identical to each other, but different from the sequences of each of the other samples, indicating the presence of a single and unique parasite species in each sample. A BLASTn search of GenBank was performed and the results are summarized in Table 5. Giraffe 229, 544, 0105 and 1505, as well as Roan 571, were each carrying a new species which was closely related to named species of Babesia. Giraffe 224, 0405 and 0505 were each carrying a new species which was closely related to named species of Theileria. 
Table 5. Highest percentage identity BLASTn hits in GenBank of the new parasite sequences obtained in this study.

\begin{tabular}{|c|c|c|c|c|c|c|c|c|}
\hline $\begin{array}{l}\text { GenBank } \\
\text { match } \\
\text { (accession } \\
\text { number) }\end{array}$ & $\begin{array}{l}\text { Giraffe } \\
229 \\
(1575 \text { bp) }\end{array}$ & $\begin{array}{l}\text { Giraffe } \\
\mathbf{5 4 4} \\
(1589 \text { bp })\end{array}$ & $\begin{array}{l}\text { Giraffe } \\
0105 \\
(1575 \text { bp) }\end{array}$ & $\begin{array}{l}\text { Giraffe } \\
1505 \\
(1591 \text { bp) }\end{array}$ & $\begin{array}{l}\text { Roan } 571 \\
\text { (1534 bp) }\end{array}$ & $\begin{array}{l}\text { Giraffe } \\
224 \\
(1589 \text { bp) }\end{array}$ & $\begin{array}{l}\text { Giraffe } \\
0405 \\
(1620 \text { bp) }\end{array}$ & $\begin{array}{l}\text { Giraffe } \\
0505 \\
(1621 \text { bp) }\end{array}$ \\
\hline $\begin{array}{l}\text { Babesia sp. } \\
\text { Xinjiang } \\
\text { (DQ159073) }\end{array}$ & $99 \%$ & $99 \%$ & $99 \%$ & $95 \%$ & $99 \%$ & & & \\
\hline $\begin{array}{l}\text { B. orientalis } \\
\text { (AY596279) }\end{array}$ & $96 \%$ & $97 \%$ & $96 \%$ & $93 \%$ & $96 \%$ & & & \\
\hline $\begin{array}{l}\text { B. occultans } \\
\text { (EU376017) }\end{array}$ & $96 \%$ & $96 \%$ & $96 \%$ & $94 \%$ & $96 \%$ & & & \\
\hline $\begin{array}{l}\text { Babesia sp. } \\
\text { Kashi } 2 \\
\text { (AY726557) }\end{array}$ & $96 \%$ & $96 \%$ & $96 \%$ & $93 \%$ & $96 \%$ & & & \\
\hline $\begin{array}{l}\text { Babesia sp. } \\
\text { (U09834) }\end{array}$ & $96 \%$ & $96 \%$ & $96 \%$ & $93 \%$ & $96 \%$ & & & \\
\hline $\begin{array}{l}\text { Babesia sp. } \\
\text { Kashi } 1 \\
\text { (AY726556) }\end{array}$ & $95 \%$ & $95 \%$ & $95 \%$ & $92 \%$ & $95 \%$ & & & \\
\hline $\begin{array}{l}\text { Babesia sp. } \\
\text { (sable) } \\
\text { (EU376016) }\end{array}$ & $95 \%$ & $95 \%$ & $95 \%$ & $93 \%$ & $95 \%$ & & & \\
\hline $\begin{array}{l}\text { T. ovis } \\
\text { (AY260171) }\end{array}$ & & & & & & $96 \%$ & $97 \%$ & $97 \%$ \\
\hline $\begin{array}{l}\text { T. capreoli } \\
(\text { AY726011) }\end{array}$ & & & & & & $96 \%$ & $97 \%$ & $97 \%$ \\
\hline $\begin{array}{l}\text { T. cervi } \\
\text { (AY735130) }\end{array}$ & & & & & & $95 \%$ & $96 \%$ & $98 \%$ \\
\hline
\end{tabular}

The maximum likelihood tree inferred from the 18S rRNA data is shown in Fig. 2. For the purpose of clarity the complete tree (Fig. 2a) groups all the species falling into the Theileria sensu stricto and Babesia sensu stricto clades as single branches. The subtrees show all the species in the Babesia sensu stricto clade (Fig. 2b) and the Theileria sensu stricto clade (Fig. 2c). The organisms from the roan antelope and four of the giraffe fall, with moderate to good bootstrap support, into the Babesia sensu stricto clade. The new species have been designated as Babesia sp. roan 571, Babesia sp. giraffe 229, 
Babesia sp. giraffe 544, Babesia sp. giraffe 0105 and Babesia sp. giraffe 1505. All of these, except Babesia sp. giraffe 1505, fall into a tight clade with Babesia sp. Xinjiang, and are closely related to a clade which includes B. orientalis, Babesia sp. Kashi 1, Babesia sp. Kashi 2, B. occultans and an unnamed Babesia species detected in a bovine in South Africa (Allsopp, 1994). Babesia sp. giraffe 1505 is the most deeply branching species in the Babesia sensu stricto clade and the bootstrap support is moderate. The remaining three new organisms fall with good bootstrap support into the Theileria sensu stricto clade and have been designated Theileria sp. giraffe 0505 , which groups with $T$. ovis, and Theileria sp. giraffe 0405 and Theileria sp. giraffe 224, which are closely related to T. capreoli, T. buffeli, T. sinensis, Theileria sp. (sable) and T. separata. 

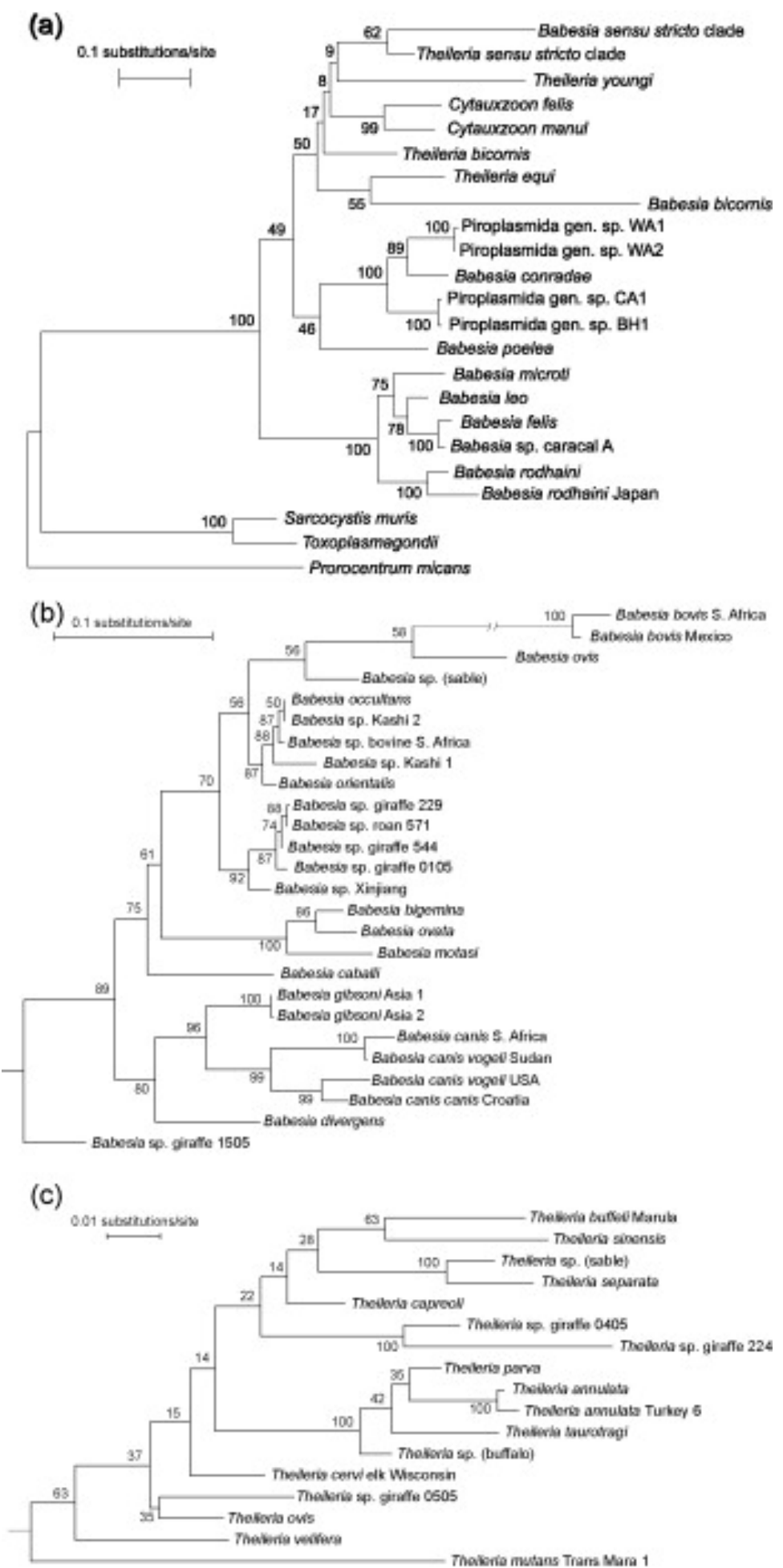

Fig. 2. Maximum likelihood tree of $18 S$ rRNA gene sequences showing the phylogenetic relationships of the Babesia and Theileria spp. obtained from the giraffe and roan antelope with other previously designated Babesia and Theileria species. The tree was outgroup rooted using Prorocentrum micans, Sarcocystis muris and Toxoplasma gondii. Bootstrap values are shown from 100 replicate trees. (a) Complete tree with the Theileria sensu stricto and Babesia sensu stricto clades shown as single branches for clarity. (b) Detail of the Babesia sensu stricto clade. Note that the Babesia bovis branch is unusually long and it has been shortened in the drawing for the sake of convenience. (c) Detail of the Theileria sensu stricto clade. 


\section{Discussion}

For many years piroplasms have been identified and classified based on their morphology, pathogenicity, host specificity, vector identity, mode of transmission and epidemiological data (Mehlhorn and Schein, 1984). Morphologically the piroplasms are broadly classified either as small $(<1.5 \mu \mathrm{m})$ or large $(>2.5 \mu \mathrm{m})$, and the two largest genera are traditionally Babesia and Theileria. Features characterizing the Babesia sensu stricto are transovarial transmission in the tick vector, and division only in erythrocytes of the vertebrate hosts. These features distinguish them from Theileria sensu stricto, which reproduce mainly in lymphocytes and are only transmitted transstadially (Mehlhorn and Schein, 1998). There are many piroplasms of dubious classification, however, which have mostly been assigned as species of Babesia, Theileria or Cytauxzoon. The advent of molecular phylogenetics has completely revolutionized systematics in the last decade and has resulted in the reclassification of numerous organisms. The gene most commonly utilized for phylogeny, the small subunit ribosomal RNA gene, has been widely used to characterize and classify previously unknown Theileria and Babesia parasites (Gubbels et al., 2000, Nijhof et al., 2003, Nijhof et al., 2005, Schnittger et al., 2003, Birkenheuer et al., 2004 and Oosthuizen et al., 2008). A difficulty remains, however, in that it has not been established by how much 18S rRNA gene sequences must differ for the source organisms to be considered different species, rather than merely a variant genotype within a species (Allsopp and Allsopp, 2006 and Chae et al., 1999), and it is doubtful that this distinction can ever be based upon the sequence of a single gene.

The RLB hybridization assay, which was developed for the simultaneous detection and identification of tick-borne parasites infecting cattle and small ruminants using 18S rRNA gene sequences (Bekker et al., 2002, Gubbels et al., 1999 and Schnittger et al., 2003), has successfully been used to discover previously undescribed Theileria and Babesia species infecting African wildlife species (Nijhof et al., 2003, Nijhof et al., 2005 and Oosthuizen et al., 2008). Subsequently 18S rRNA gene sequence analyses have been used to improve the descriptions of these species.

\subsection{The identification of Babesia spp. in giraffe and roan antelope}

The adult giraffe which died from sudden disease onset were examined in this study for the presence of Theileria and/or Babesia spp. Four cases (giraffe 229, giraffe 544, giraffe 0105 and giraffe 1505) showed typical clinical signs of babesiosis, including anaemia, hemoglobinuria, pale to icteric mucous membranes, and depression. Rhipicephalus appendiculatus ticks were collected from giraffe 0105, and giraffe 544 was reported to have had a severe tick burden but none of the ticks were collected. Microscopic examination of thin blood smears of samples from giraffe 0105 and giraffe 229 
demonstrated the presence of a Babesia-like parasite and the RLB assay suggested that novel species or variants of species were present. The $18 \mathrm{~S}$ rRNA gene sequence data and phylogenetic analysis confirmed that a Babesia sensu stricto organism was present in all four cases and these were designated Babesia sp. giraffe 229, Babesia sp. giraffe 544, Babesia sp. giraffe 0105 and Babesia sp. giraffe 1505. The first three of these formed a monophyletic group with Babesia sp. Xinjiang and were closely related to B. orientalis, Babesia sp. Kashi 1, Babesia sp. Kashi 2, B. occultans and an unnamed Babesia species from a bovine. In a recent study (Oosthuizen et al., 2008), we suggested that the latter unnamed species, as well as Babesia sp. Kashi 1 and 2 could possibly be variants of B. occultans. Babesia sp. (sable), recently identified in a sable antelope in South Africa (Oosthuizen et al., 2008) was also closely related to these organisms as well as to B. bovis.

A 3-month-old roan antelope calf, born in the Mkhaya Wildlife Sanctuary, Swaziland, in the eastern Lowveld against the Lebombo Mountains, was also part of this study. Due to heavy mortality from theileriosis, roan antelope calves were treated prophylactically with buparvaquone. This procedure was performed every 2 weeks and EDTA blood samples were collected simultaneously and submitted for RLB hybridization. As far as we know, roan 571 did not succumb to any disease. The $18 \mathrm{~S}$ rRNA gene sequence analysis revealed the presence of another Babesia sensu stricto organism, designated Babesia sp. roan 571. This organism also fell into the Babesia sp. Xinjiang clade and was very closely related to the other new organisms in that clade. It is possible that Babesia sp. giraffe 229, Babesia sp. giraffe 554, Babesia sp. giraffe 0105 and Babesia sp. roan 571 could constitute variants of one Babesia species. Babesia sp. Xinjiang, originally detected from a batch of mixed Rhipicephalus sanguineus and Hyalomma a. anatolicum ticks from Kashi, Xinjiang province, China, was described as often leading to clinically inapparent infection in sheep (Liu et al., 2007). The double pyriform parasites measure 3.0$4.0 \mu \mathrm{m} \times 1.1-2.1 \mu \mathrm{m}$ (Guan et al., 2001) and this is therefore considered to be a large Babesia (Liu et al., 2007). Rhipicephalus sanguineus or H. a. anatolicum ticks are suspected to be the transmission vector of Babesia sp. Xinjiang (Liu et al., 2007) and, while the vector of the giraffe/roan Babesia remains unknown, Rhipicephalus appendiculatus was among the ticks collected from giraffe 0105 . Additional molecular data, as well as information on the tick vectors, host ranges and other biological properties, are required to clarify whether Babesia sp. Xinjiang is conspecific with the giraffe/roan Babesia organisms.

\subsection{Identification of Theileria spp. in giraffe}

A further three giraffe cases were investigated during this study. Giraffe specimens 0405 and 0505 were collected during translocation of the animals from Kimberley, Northern Cape province. Unfortunately we have no information on the current location of these animals or their health status upon arrival. Giraffe 224 had been translocated from Namibia to Reddersburg, Free State province, and shortly after arrival the 
sudden onset of illness resulted in rapid death. Thin blood smears from the animal revealed the presence of a Theileria-like parasite. In all three cases RLB hybridization results suggested the presence of novel Theileria species or variants and the phylogenetic analysis placed the organisms in the Theileria sensu stricto clade. The new organisms were designated Theileria sp. giraffe 0505, Theileria sp. giraffe 0405 and Theileria sp. giraffe 224. Theileria sp. giraffe 0505 grouped with T. ovis, which is a benign Theileria species found in sheep and goats and is vectored by Rhipicephalus bursa and R. evertsi evertsi (Levine, 1985). Theileria sp. giraffe 0405 and Theileria sp. giraffe 224 grouped together in close relation to $T$. capreoli, and a group of Theileria including T. buffeli, T. sinensis, Theileria sp. (sable) and T. separata. Our results support previous morphological data indicating the presence of both Babesia and Theileria spp. in giraffe. It should be noted, however, that all of the parasites examined in this study were identified in giraffe originating from southern African countries, so we cannot be certain that these sequences are also representative of parasites in East African giraffe.

Based on molecular phylogenetic analyses the piroplasms have been separated into four major groups: (i) the true babesias, Babesia, (ii) Theileria and Cytauxzoon species, (iii) the western United States piroplasms from wildlife and humans, and (iv) B. microti and related small babesias (Kjemtrup and Conrad, 2006). Our phylogenetic tree (Fig. 2) shows a relatively similar pattern, where we have called the true babesias the Babesia sensu stricto clade, but there is nothing similar to group (ii). There is one wellsupported clade which incorporates the Theileria species over which there is no controversy, which we have called the Theileria sensu stricto clade. In addition, a number of organisms of uncertain classification appear to have branched off quite early from the evolutionary line which led to the common ancestor of the Theileria sensu stricto species. These disparate organisms include species of Cytauxzoon, which has long been a controversial genus, as well as T. youngi, T. bicornis, T. equi and B. bicornis. These organisms do not fall into a single clade in our analysis, but the bootstrap support which places them in separate groups is very weak and it is possible that they could constitute a separate clade. What is certain, however, is that these organisms belong neither in the Theileria sensu stricto clade nor in the group of western United States piroplasms from wildlife and humans. Improved classification of these organisms will require the acquisition of further genetic, epidemiological and life cycle data. In summary, 18S rRNA gene sequence similarity analysis revealed the presence of novel piroplasm species in both healthy giraffe and a roan antelope and clinically sick or dead giraffe. Phylogenetic analysis grouped five of these organisms in the Babesia sensu stricto clade and three in the Theileria sensu stricto clade. Although parasites were observed in blood smears there is no direct evidence that piroplasmosis caused the death of five giraffe, although it certainly seems to be likely. It is not known whether these were isolated incidents or whether the parasites frequently cause severe disease in giraffe, but at least one giraffe (224) had been translocated from Namibia shortly before the disease manifested. It 
may either have been exposed to the parasite in its new location or the stress of the move may have triggered the disease.

\section{Acknowledgements}

This research was supported by a South African National Research Foundation grant (NRF grant GUN 2069496). We thank the veterinarians for submitting the giraffe and roan antelope specimens, as well as Raksha Bhoora for technical assistance with the RLB.

\section{References}

Altschul et al., 1990 S.F. Altschul, W. Gish, W. Miller, E.W. Myers and D.J. Lipman, Basic local alignment search tool, J. Mol. Biol. 215 (1990), pp. 403-410.

Allsopp and Allsopp, 2006 M.T. Allsopp and B.A. Allsopp, Molecular sequence evidence for the reclassification of some Babesia species, Ann. N. Y. Acad. Sci. 1081 (2006), pp. 509-517.

Allsopp, 1994 M.T.E.P. Allsopp, The Phylogeny of Babesia, Theileria and Related Parasites and the Development of Species-Specific Probes for Diagnostic Purposes, University of the Witwatersrand, Johannesburg, South Africa (1994).

Bekker et al., 2002 C.P.J. Bekker, S. de Vos, A. Taoufik, O.A.E. Sparagano and F. Jongejan, Simultaneous detection of Anaplasma and Ehrlichia species in ruminants and detection of Ehrlichia ruminantium in Amblyomma variegatum ticks by reverse line blot hybridization, Vet. Microbiol. 89 (2002), pp. 223-238.

Birkenheuer et al., 2004 A.J. Birkenheuer, J. Neel, D. Ruslander, M.G. Levy and E.B. Breitschwerdt, Detection and molecular characterization of a novel large Babesia species in a dog, Vet. Parasitol. 124 (2004), pp. 151-160.

Bonfield et al., 1995 J.K. Bonfield, K.F. Smith and R. Staden, A new DNA sequence assembly program, Nucleic Acids Res. 23 (1995), pp. 4992-4999.

Brocklesby and Vidler, 1965 D.W. Brocklesby and B.O. Vidler, Some parasites of East African wild animals, E. Afr. Wildl. J. 3 (1965), pp. 120-122. 
Chae et al., 1999 J.S. Chae, B.A. Allsopp, S.D. Waghela, J.H. Park, T. Kakuda, C. Sugimoto, M.T.E.P. Allsopp, G.G. Wagner and P.J. Holman, A study of the systematics of Theileria spp. based upon smallsubunit ribosomal RNA gene sequences, Parasitol. Res. 85 (1999), pp. 877-883.

Grootenhuis et al., 1979 J.G. Grootenhuis, A.S. Young, T.T. Dolan and P.A. Stagg, Characteristics of Theileria species (eland) infection in eland and cattle, Res. Vet. Sci. 27 (1979), pp. 59-68.

Grootenhuis et al., 1980 J.G. Grootenhuis, W.I. Morrison, L. Karlstad, P.D. Sayer, A.S. Young, M. Murray and R.D. Haller, Fatal theileriosis in eland (Taurotragus oryx), pathology of natural and experimental cases, Res. Vet. Sci. 29 (1980), pp. 219-229.

Gubbels et al., 1999 J.M. Gubbels, A.P. de Vos, M. van der Weide, J. Viseras, L.M. Schouls, E. de Vries and F. Jongejan, Simultaneous detection of bovine Theileria and Babesia species by reverse line blot hybridization, J. Clin. Microbiol. 37 (1999), pp. 1782-1789.

Gubbels et al., 2000 M. Gubbels, Y. Hong, M. van der Weide, B. Qi, I.S. Nijman, L. Guangyuan and F. Jongejan, Molecular characterisation of the Theileria buffeli/orientalis group, Int. J. Parasitol. 30 (2000), pp. 943-952.

Guan et al., 2001 G.Q. Guan, H. Yin and J.X. Luo, The primary studies on morphology and pathogenicity on an unidentified large ovine Babesia, Chin. J. Vet. Sci. Technol. 11 (2001), pp. 35-36.

Guindon and Gascuel, 2003 S. Guindon and O. Gascuel, A simple, fast, and accurate algorithm to estimate large phylogenies by maximum likelihood, Syst. Biol. 52 (2003), pp. 696-704.

Kjemtrup and Conrad, 2006 A.M. Kjemtrup and P.A. Conrad, A review of the small canine piroplasms from California: Babesia conradae in the literature, Vet. Parasitol. 138 (2006), pp. 112-117.

Krecek et al., 1990 R.C. Krecek, J. Boomker, B.L. Penzhorn and L. Scheepers, Internal parasites of giraffes (Giraffa camelopardalis angolensis) from Etosha National Park, Namibia, J. Wildl. Dis. 26 (1990), pp. 395-397.

Levine, 1985 N.D. Levine, Veterinary Protozoology, Iowa State University Press, Ames (1985). 
Liu et al., 2007 A.H. Liu, H. Yin, G.Q. Guan, L. Schnittger, Z.J. Liu, M.L. Ma, Z.S. Dang, J.L. Liu, Q.Y. Ren, Q. Bai, J.S. Ahmed and J.X. Luo, At least two genetically distinct large Babesia species infective to sheep and goats in China, Vet. Parasitol. 147 (2007), pp. 246-251.

McCully et al., 1970 R.M. McCully, M.E. Keep and P.A. Basson, Cytauxzoonosis in a giraffe [Giraffa camelopardalis (Linnaeus, 1758)] in Zululand, Onderstepoort J. Vet. Res. 37 (1970), pp. 7-10.

Mehlhorn and Schein, 1984 H. Mehlhorn and E. Schein, The piroplasms: life-cycle and sexual stages. In: J.R. Baker and R. Muller, Editors, Advances in Parasitology 23, Academic Press, London (1984), pp. 37103.

Mehlhorn and Schein, 1998 H. Mehlhorn and E. Schein, Redescription of Babesia equi Laveran, 1901 as Theileria equi Mehlhorn, Schein 1998, Parasitol. Res. 84 (1998), pp. 467-475.

Nijhof et al., 2003 A.M. Nijhof, B.L. Penzhorn, G. Lyenn, J.O. Mollel, P. Morkel, C.D.J. Bekker and F. Jongejan, Babesia bicornis sp. nov. and Theileria bicornis sp. nov: tick-borne parasites associated with mortality in the black rhinoceros (Diceros bicornis), J. Clin. Microbiol. 203 (2003), pp. 2249-2254.

Nijhof et al., 2005 A.M. Nijhof, V. Pillay, J. Steyl, W.H. Prozesky, W.H. Stoltsz, J.A. Lawrence, B.L. Penzhorn and F. Jongejan, Molecular characterisation of Theileria species associated with mortality in four species of African antelopes, J. Clin. Microbiol. 43 (2005), pp. 5907-5911.

Norval et al., 1992 In: R.A.I. Norval, B.D. Perry and A.S. Young, Editors, The Epidemiology of Theileriosis in Africa, Academic Press, London, UK (1992).

Oosthuizen et al., 2008 M.C. Oosthuizen, E. Zweygarth, M.E. Collins, M. Troskie and B. Penzhorn, Identification of a novel Babesia sp. from a sable antelope (Hippotragus niger Harris, 1838), J. Clin. Microbiol. 46 (2008), pp. 2247-2251.

Perry et al., 1991 B.D. Perry, R. Kruska, P. Lessard, R.A.I. Norval and K. Kundert, Estimating the distribution and abundance of Rhipicephalus appendiculatus in Africa, Prev. Vet. Med. 11 (1991), pp. 261-268. 
Schnittger et al., 2003 L. Schnittger, H. Yin, M.J. Gubbels, D. Beyer, S. Niemann, F. Jongejan and J.S. Ahmed, Phylogeny of sheep and goat Theileria and Babesia parasites, Parasitol. Res. 91 (2003), pp. 398406.

Staden, 1996 R. Staden, The Staden sequence analysis package, Mol. Biotechnol. 5 (1996), pp. 233-241.

Staden et al., 2000 R. Staden, K.F. Beal and J.K. Bonfield, The Staden sequence analysis package, Mol. Biotechnol. 5 (2000), pp. 233-241.

Thompson et al., 1994 J.D. Thompson, D.G. Higgins and T.J. Gibson, CLUSTAL W: improving the sensitivity of progressive multiple sequence alignment through sequence weighting, position-specific gap penalties and weight matrix choice, Nucleic Acids Res. 22 (1994), pp. 4673-4678.

Uilenberg et al., 1982 G. Uilenberg, N.M. Perie, J.A. Lawrence, A.J. de Vos, R.W. Paling and A.A. Spanjer, Causal agents of bovine theileriosis in Southern Africa, Trop. An. Hlth. Prod. 14 (1982), pp. $127-140$.

Wilson et al., 1974 D.E. Wilson, R.C. Bartsch, R.D. Bigalke and S.E. Thomas, Observations on mortality rates and disease in roan and sable antelope on nature reserves in the Transvaal, J. S. Afr. Wildl. Mgmt. Assoc. 4 (1974), pp. 203-206.

Worthington and Bigalke, 2001 R.W. Worthington and R.D. Bigalke, A review of the infectious diseases of African wild ruminants, Onderstepoort J. Vet. Res. 68 (2001), pp. 291-323. 